\title{
Rainfall trend analysis and geospatial mapping of the Kelantan River Basin
}

\begin{abstract}
Trend analysis was widely used as a tool to detect changes in climatic and hydrologic time series data such as rainfall. Fourteen rainfall stations in the Kelantan River Basin were used to detect trends for each of the sub-basin areas. Two objectives of the study are (i) to quantify the changing trends of rainfall of Kelantan River using statistical tests (i.e., Mann-Kendall test and Senôs slope test) based on monthly, seasonal, and annual time series, and secondly, (ii) to map rainfall trend according to Mann-Kendall test result. Analysis for these two tests revealed that several stations indicated significant increasing and decreasing trends for monthly, seasonal, and annual rainfall time series. The study found that rainfall varies in different months, seasons, and annually as evidenced by the graph and trend maps. Therefore, this information will benefit especially for flood preparation and responses in Kelantan River Basin which annually experiences monsoon flooding.
\end{abstract}

Keyword: Rainfall time series; Mann-Kendall test; Sen's slope estimator; Kriging interpolation 